\title{
High Temperature Deformation Behavior of 8090 Al-Li Alloy
}

\author{
Woo Young Jung ${ }^{1}$ and Tae Kwon $\mathrm{Ha}^{2}$ \\ ${ }^{1}$ Department of Civil Engineering, Gangneung-Wonju National University, 120 Gangneung-Daehangno, Gangneung, \\ Gangwon 210-702, Republic of Korea \\ ${ }^{2}$ Department of Advanced Metal and Materials Engineering, Gangneung-Wonju National University, \\ 120 Gangneung-Daehangnu, Gangneung, Gangwon 210-702, Republic of Korea
}

Correspondence should be addressed to Tae Kwon Ha; tkha@gwnu.ac.kr

Received 25 March 2013; Accepted 17 June 2013

Academic Editor: S. Miyazaki

Copyright (C) 2013 W. Y. Jung and T. K. Ha. This is an open access article distributed under the Creative Commons Attribution License, which permits unrestricted use, distribution, and reproduction in any medium, provided the original work is properly cited.

\begin{abstract}
High temperature deformation behavior, especially the superplasticity of an 8090 Al-Li alloy, was studied within the recent framework of the internal variable theory of structural superplasticity. In this study, a series of load relaxation tests were conducted at various temperatures ranging from $200^{\circ} \mathrm{C}$ to $530^{\circ} \mathrm{C}$ to obtain the flow curves of $\log \dot{\varepsilon}$ versus $\log \varepsilon$. The effect of grain size was also examined by varying the grain sizes through a proper thermomechanical treatment. The flow curves were found to be composite curves consisting of contributions from grain boundary sliding (GBS) and grain matrix deformation (GMD) at superplastic temperatures. The activation energy obtained for GMD was $124.9 \mathrm{~kJ} / \mathrm{mole}$ in the temperature range from $470^{\circ} \mathrm{C}$ to $530^{\circ} \mathrm{C}$, very similar to that for self-diffusion in pure $\mathrm{Al}$.
\end{abstract}

\section{Introduction}

The high temperature deformation behavior, including superplasticity, of crystalline materials has generally been described phenomenologically by a power-law relation between the two external variables, namely, flow stress $(\sigma)$ and strain rate $(\dot{\varepsilon})$, as follows $[1,2]$ :

$$
\sigma=B \dot{\varepsilon}^{m},
$$

where $B$ is a constant. The strain rate sensitivity parameter, $m$, can then be defined as the slope of the $\log \sigma$ versus $\log \dot{\varepsilon}$ curves. This parameter has widely been used as one of the most important parameters characterizing the superplastic deformation behavior [1-3]. The value of $m$ is, however, observed to vary continuously along the $\log \sigma$ versus $\log \dot{\varepsilon}$ curves, unable to provide a critical value above which superplastic deformation can be predicted [4]. When it comes to structural superplasticity (SSP), it is apparent that the external or phenomenological variables such as $\sigma, \varepsilon$, and $\dot{\varepsilon}$ alone cannot adequately describe SSP.

Superplasticity is a deformation process that produces large elongation of more than several hundred percent in crystalline materials, usually deformed in tension at a very low level of stress. Grain boundary sliding (GBS) is widely accepted as the most important deformation mechanism of superplasticity. In general, superplastic properties are exhibited in materials having a stable, equiaxed, and extremely fine microstructure only under a very narrow range of strain rate and temperature normally above $0.5 T_{M}$, where $T_{M}$ is an absolute melting temperature [3].

A new approach to structural superplasticity (SSP) has been made by taking the dislocation glide mechanism as the major accommodation process for GBS [5], instead of the generally accepted high temperature diffusion process [6]. The justification for this approach comes from the observation that the superplastic deformation usually occurs in the strain rate range coinciding with that of plastic deformation caused by a dislocation glide.

After obtaining the various grain sizes through a proper thermomechanical treatment, a series of load relaxation and tensile tests were conducted at temperatures ranging from $200^{\circ} \mathrm{C}$ to $530^{\circ} \mathrm{C}$ in this study. The load relaxation test provided the flow data in a much wider range of strain rate with minimal microstructural change or constant microstructure during the test $[7,8]$, making it possible to analyze the flow curves within the framework of the internal variable theory of SSP. The effect of grain size and temperature on the flow behavior of 8090 Al-Li alloy was specifically investigated 


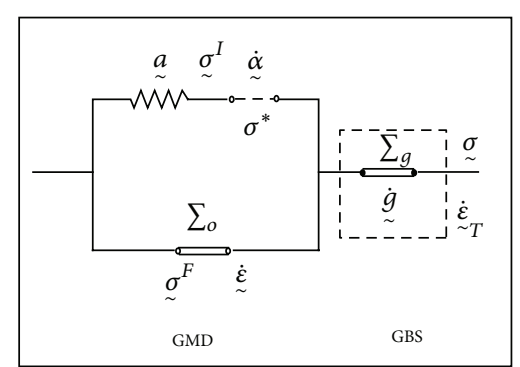

FIGURE 1: A rheological model representing the GBS accommodated by GMD [5].

based on the internal variable theory of SSP, and a critical condition for superplastic deformation is proposed. The next section provides a brief description of the internal variable theory of SSP.

\section{Internal Variable Theory of SSP}

The typical internal variable model, proposed by Chang and Aifantis [9], has described in detail a constitutive framework to consider inelastic deformation based on the notion of internal strain and internal spin tensors together with their precise micromechanical origin. Repeating here some important concepts of the model, a simple rheological model has been proposed by considering the grain matrix deformation (GMD) as a major accommodating process for GBS [5]. The two deformation mechanisms, that is, GBS and GMD, compete with each other in high temperature deformation of polycrystalline materials when it is not confined to SSP.

An elementary material volume $V$ bounded by the surface $S$ within and across which dislocations are allowed to move in response to a stress field $(\underset{\sim}{\sigma})$ is considered here. When the material boundary acts as a strong barrier partially blocking the passage of dislocations, some of dislocations would remain inside the material volume, giving rise to an internal strain $(a)$, while at the same time the rest of the dislocations will pass through to produce an externally observable plastic deformation $(\underset{\alpha}{\dot{\alpha}})$. These simultaneous processes of accumulation within $\widetilde{V}$ and the passage through $S$ of dislocations are believed to be the most fundamental deformation mechanism responsible for various mechanical phenomena, such as plasticity [10], phase transformation [11], and fracture.

Instead of using the phenomenological power law relation between $\sigma$ and $\dot{\varepsilon}$, a simple rheological model is used in this study. This model given in Figure 1 shows that GBS is mainly accommodated by a dislocation process, giving rise to an internal strain $(a)$ and plastic strain rate $(\dot{\alpha})$. For the model given in Figure 1, we derived the following stress relation and kinematic relation among the deformation rate variables, $\underset{\sim}{a}$, $\underset{\sim}{\dot{\alpha}}$, and $\dot{\dot{g}}$, due to GBS:

$$
\begin{aligned}
\underset{\sim}{\sigma} & =\underset{\sim}{\sigma^{I}}+\sigma^{F}, \\
\underset{\sim}{\dot{\varepsilon}} & =\underset{\sim}{\stackrel{\circ}{a}}+\underset{\sim}{\dot{\alpha}}+\dot{g} .
\end{aligned}
$$

The internal variables ${\underset{\sim}{\sigma}}^{I}$ and ${\underset{\sim}{\sigma}}^{F}$ represent the internal stress required to overcome a long-range interaction force

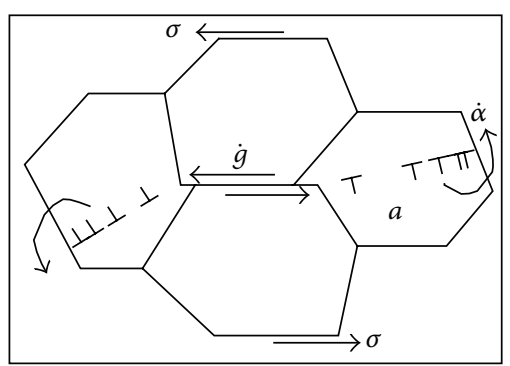

Figure 2: A topological model for SSP [5].

among glide dislocations and the friction stress to surmount a short-range interaction force between dislocations and lattices, respectively. The time rate $\underset{\sim}{a}$ denotes the materials time rate [12] of change of internal strain tensor similar to that prescribed by Hart [13]. A topological representation for this model is given in Figure 2.

The constitutive relations between the stress variables and the deformation rate variables for grain matrix plastic deformation have been prescribed [5] in a form similar to that of Hart [13] from the viewpoint of simple dislocation kinetics. These relations can be written as follows:

$$
\begin{gathered}
\left(\frac{\sigma^{*}}{\sigma^{I}}\right)=\exp \left(\frac{\dot{\alpha}^{*}}{\dot{\alpha}}\right)^{p}, \\
\dot{\alpha}^{*}=v^{I}\left(\frac{\sigma^{*}}{\mu}\right)^{n^{I}} \exp \left(\frac{-Q^{I}}{R T}\right), \\
\left(\frac{\dot{\varepsilon}}{\dot{\varepsilon}_{o}}\right)=\left(\frac{\sigma}{\Sigma_{o}}-1\right)^{1 / M}, \\
\dot{\varepsilon}_{o}=v^{F}\left(\frac{\Sigma_{o}}{G}\right)^{n^{F}} \exp \left(\frac{-Q^{F}}{R T}\right),
\end{gathered}
$$

where $p, M, n^{I}$, and $n^{F}$ are the material constants. $\sigma^{*}$ and $\dot{\alpha}^{*}$ in (4) are the internal strength variable and its conjugate reference strain rate, respectively, and they are related by (5) with $\nu^{I}$ jump frequency, $Q^{I}$ an activation energy, and $\mu$ an internal modulus [5]. Equation (4) is, in fact, a kinetic rate equation of a mechanical activation process for a leading dislocation to overcome grain boundaries. Equation (6) represents the friction glide process of dislocations in lattice. $\Sigma_{o}$ and $\dot{\varepsilon}_{o}$ are the static friction stress and its conjugate reference strain rate, and they are related by (7) with $\nu^{F}$ jump frequency, $Q^{F}$ an activation energy for this process, and $G$ a shear modulus.

Considering the GBS as a viscous drag process similar to the frictional glide process of dislocations, the following power-law relation has been prescribed as [5]

$$
\begin{gathered}
\left(\frac{\dot{g}}{\dot{g}_{o}}\right)=\left(\frac{\sigma}{\Sigma_{g}}-1\right)^{1 / M_{g}}, \\
\dot{g}_{o}=v^{g}\left(\frac{\Sigma_{g}}{\mu_{g}}\right)^{n^{g}} \exp \left(\frac{-Q^{g}}{R T}\right),
\end{gathered}
$$


TABLE 1: The chemical composition (wt.\%) of $8090 \mathrm{Al}-\mathrm{Li}$ alloy used in this study.

\begin{tabular}{lccccccc}
\hline $\mathrm{Cu}$ & $\mathrm{Fe}$ & $\mathrm{Mg}$ & $\mathrm{Si}$ & $\mathrm{Zr}$ & $\mathrm{Zn}$ & $\mathrm{Li}$ & \\
\hline 1.24 & 0.05 & 0.9 & 0.02 & 0.11 & 0.04 & $\mathrm{Al}$ \\
\hline
\end{tabular}
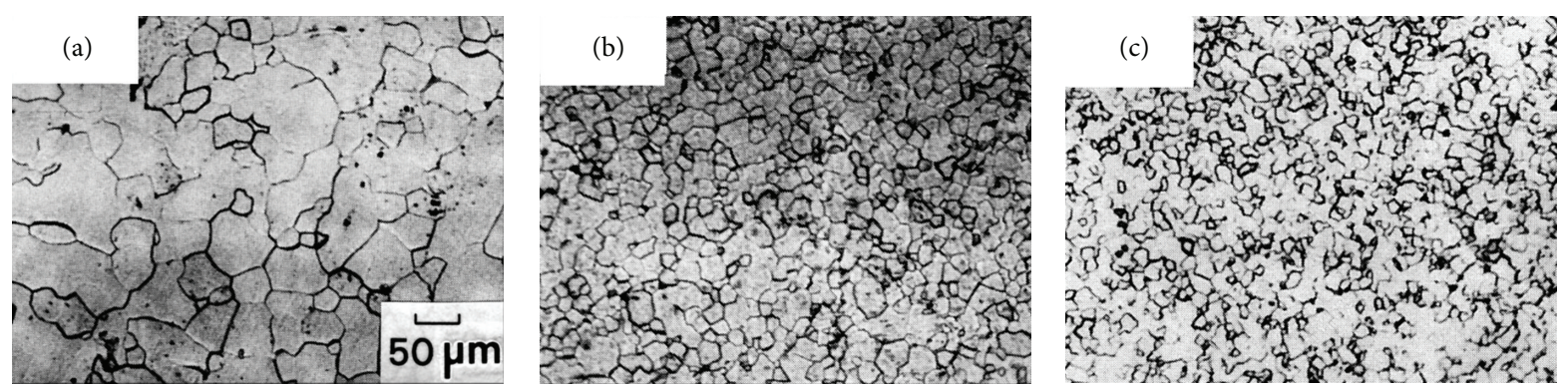

FIGURE 3: Optical micrographs of thermomechanically treated 8090 Al-Li alloy with the average grain size of (a) $50 \mu \mathrm{m}$, (b) $18 \mu \mathrm{m}$, and (c) $10 \mu \mathrm{m}$, respectively.

where $M_{g}$ and $n^{g}$ denote material constants. The constitutive parameters $\Sigma_{g}$ and $\dot{g}_{o}$ are the static friction stress and its conjugate reference rate for GBS, respectively. Equation (8) is again viewed as a thermally activated process of GBS with $\mathrm{Q}^{g}$ now denoting the activation energy for GBS.

At high temperature range as that used in this study, $\sigma^{F}$ is in general very small compared to ${\underset{\sim}{\sigma}}^{I}$, and $\underset{\sim}{a}$ can be neglected if the relaxation test is conducted uniaxially at a steady state. We can, therefore, describe high temperature deformation behavior of crystalline materials with the constitutive relations for $\underset{\sim}{\dot{\alpha}}$ and $\dot{g}$ elements.

\section{Experimental Procedure}

The 8090 A1-Li alloy used in this study was supplied in the form of a plate with the thickness of $44.5 \mathrm{~mm}$, solutiontreated, $6 \%$ stretched, and naturally aged condition (T3771). This material, known as LITHAL together with $8091 \mathrm{Al}-\mathrm{Li}$ alloy in generic name, had the chemical composition given in Table 1. A proper thermomechanical treatment (TMT) is required before expecting the superplasticity for this alloy, because the as-received material has elongated and pancakeshaped microstructure. The basic concept of thermomechanical treatment (for grain refinement of precipitation hardening aluminum alloy) proposed by Wert et al. [14] was employed with some modifications in this study.

The as-received plate was first solution treated at $530^{\circ} \mathrm{C}$ for $3 \mathrm{hrs}$ followed by a rapid quenching in cold water. The plate was then overaged at $400^{\circ} \mathrm{C}$ for $12 \mathrm{hrs}$. The specimen with a larger grain size of $d=50 \mu \mathrm{m}$ was obtained by recrystallizing at $530^{\circ} \mathrm{C}$ for $3 \mathrm{hrs}$ in a salt bath after warm rolling at $300^{\circ} \mathrm{C}$. After an additional overaging and cold rolling process, finer grain sizes of $d=10 \mu \mathrm{m}$ and $d=$ $18 \mu \mathrm{m}$ were obtained by recrystallizing at $530^{\circ} \mathrm{C}$ and $580^{\circ} \mathrm{C}$ for $1 \mathrm{hr}$, respectively. All specimens after the recrystallization process were directly quenched into cold water. The optical micrographs of thermomechanically treated specimens are given in Figure 3.
Load relaxation tests were then carried out at various temperatures between $200^{\circ} \mathrm{C}$ and $530^{\circ} \mathrm{C}$ by using a computer-controlled electromechanical testing machine attached with a high temperature furnace capable of maintaining the temperature fluctuation within $\pm 0.5^{\circ} \mathrm{C}$. The specimens for the load relaxation test have a square crosssection $(2 \mathrm{~mm} \times 2 \mathrm{~mm})$ with $15 \mathrm{~mm}$ gauge length. In the load relaxation test employed in this study, a specimen was loaded first in tension to a certain predetermined extension value followed by stopping cross-head motion. The load was then recorded as a function of time at the fixed cross-head position. The variation of the load $(p)$ was monitored through a digital voltmeter (HP 3456A DVM) and stored in a personal computer for further processing. The flow stress $\sigma$ and inelastic strain rate $\dot{\varepsilon}$ were then calculated from the load-time data following the usual procedure described in the literature [15].

Tensile tests were also performed at the temperature range mentioned previously under the various initial strain rates ranging from $10^{-2} / \mathrm{s}$ to $5 \times 10^{-4} / \mathrm{s}$. The tensile test specimens were plate type with dimensions of $2 \mathrm{~mm}$ in thickness and $5 \mathrm{~mm}$ in gauge length. All specimens were pulled to fracture at a constant cross-head speed.

\section{Experimental Results}

4.1. Load Relaxation Tests. The relaxation test results obtained at various temperatures are shown in Figure 4 for the specimens with the average grain size of $50 \mu \mathrm{m}$. The flow curves shifted noticeably toward the lower stress and the higher strain rate region as the temperature increases from $200^{\circ} \mathrm{C}$ to $530^{\circ} \mathrm{C}$. The values of constitutive parameters were determined by fitting the experimental data to (4), and the results are presented in Table 2. The solid lines in Figure 4 are the predicted curves representing the flow behavior of $\dot{\alpha}$ element described by (4) constructed with the constitutive parameters listed in Table 2. They show a good agreement with experimental data. It is clear from the figure that the specimens with such a large grain size reveal only 


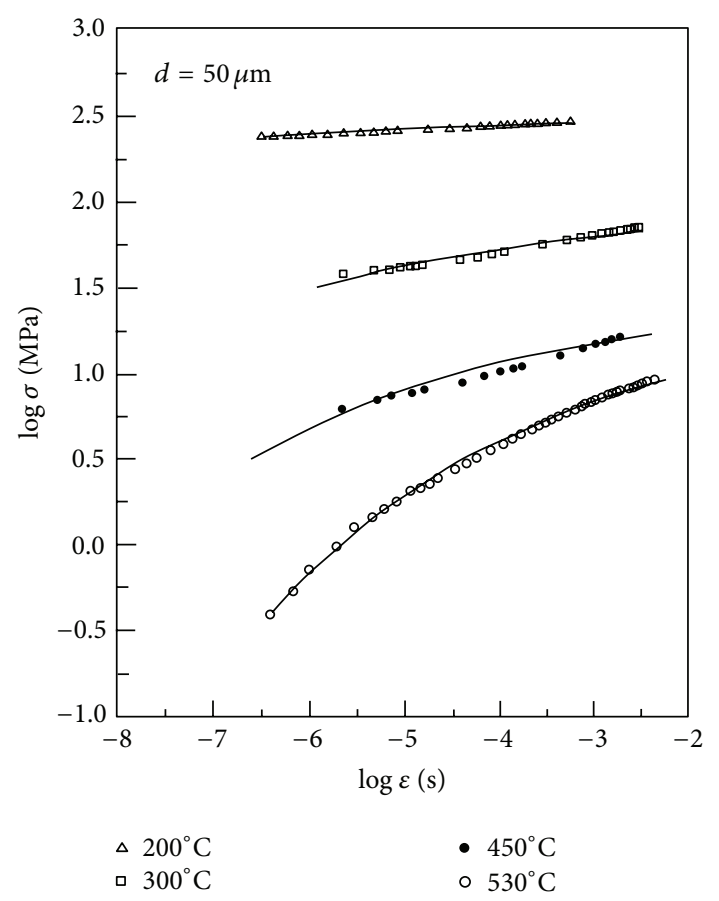

FIgURE 4: The effect of temperature on the flow behavior of 8090 $\mathrm{Al}-\mathrm{Li}$ with the average grain size of $50 \mu \mathrm{m}$.

TABLE 2: The constitutive parameters for $\dot{\alpha}$ element determined from the load relaxation test results of $8090 \mathrm{Al}-\mathrm{Li}$ with the grain size of $50 \mu \mathrm{m}$.

\begin{tabular}{lccc}
\hline Temp. $\left({ }^{\circ} \mathrm{C}\right)$ & $\log \sigma^{*}$ & $\log \dot{\alpha}^{*}$ & $P$ \\
\hline 200 & 2.49 & -10.25 & 0.15 \\
300 & 1.96 & -5.69 & 0.15 \\
450 & 1.45 & -4.35 & 0.15 \\
530 & 1.39 & -2.03 & 0.15 \\
\hline
\end{tabular}

the plastic deformation behavior of $\dot{\alpha}$ element regardless of test temperatures.

A very similar result was obtained for the specimens with the average grain size of $18 \mu \mathrm{m}$ except at $530^{\circ} \mathrm{C}$ as shown in Figure 5. The flow curve at $530^{\circ} \mathrm{C}$ shows a concave portion within the strain rate range of roughly $10^{-5} / \mathrm{s} \leq \dot{\varepsilon} \leq 10^{-3} / \mathrm{s}$, indicating the existence of some contributions from GBS. The solid lines in Figure 5 again represent the predicted curves from (4) constructed with the values of constitutive parameters listed in Table 3, and they are also in good accord with the experimental data.

The flow curves of specimens with the average grain size of $10 \mu \mathrm{m}$ are given in Figure 6, and the determined constitutive parameters are presented in Table 4 . For the purpose of obtaining an activation energy for plastic deformation, a relatively narrow range of temperature has been chosen for specimens of $d=10 \mu \mathrm{m}$. Again, only the plastic flow behavior of $\dot{\alpha}$ element could be observed at the lower temperatures of $470^{\circ} \mathrm{C}$ and $490^{\circ} \mathrm{C}$. The flow curve obtained at $530^{\circ} \mathrm{C}$, on the other hand, showed more noticeable concave portion within a strain rate range much broader than the flow

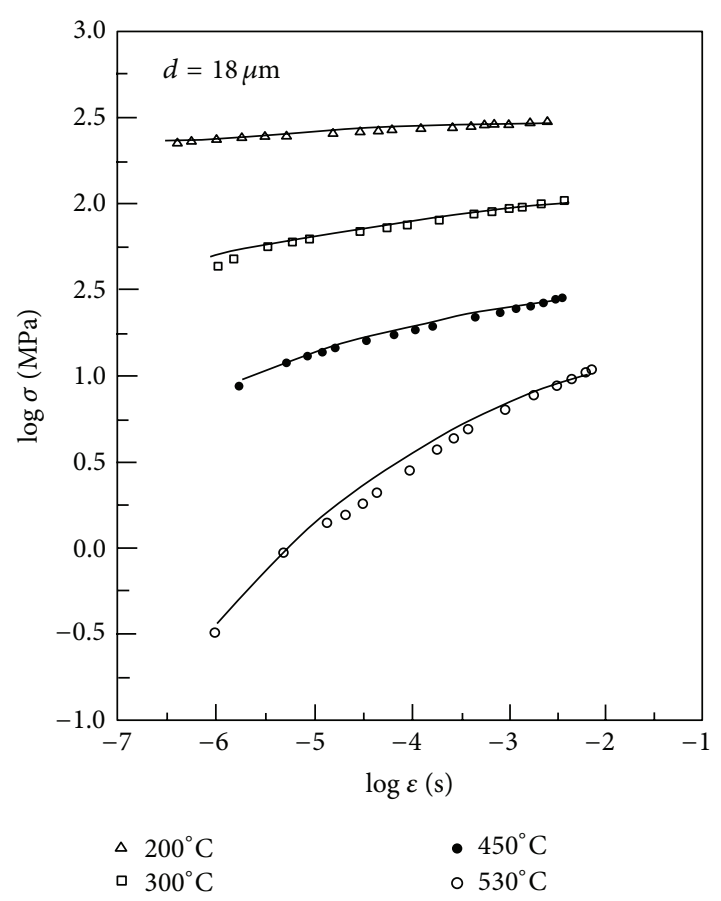

FIGURE 5: The effect of temperature on the flow behavior of 8090 $\mathrm{Al}-\mathrm{Li}$ with the average grain size of $18 \mu \mathrm{m}$.

TABLE 3: The constitutive parameters for $\dot{\alpha}$ element determined from the load relaxation test results of $8090 \mathrm{Al}-\mathrm{Li}$ with the grain size of $18 \mu \mathrm{m}$.

\begin{tabular}{lccc}
\hline Temp. $\left({ }^{\circ} \mathrm{C}\right)$ & $\log \sigma^{*}$ & $\log \dot{\alpha}^{*}$ & $P$ \\
\hline 200 & 2.52 & -9.27 & 0.15 \\
300 & 2.17 & -5.36 & 0.15 \\
450 & 1.66 & -4.44 & 0.15 \\
530 & 1.55 & -1.06 & 0.15 \\
\hline
\end{tabular}

TABLE 4: The constitutive parameters for $\dot{\alpha}$ element determined from the load relaxation test results of $8090 \mathrm{Al}-\mathrm{Li}$ with the grain size of $10 \mu \mathrm{m}$.

\begin{tabular}{lccc}
\hline Temp. $\left({ }^{\circ} \mathrm{C}\right)$ & $\log \sigma^{*}$ & $\log \dot{\alpha}^{*}$ & $P$ \\
\hline 470 & 1.87 & -1.47 & 0.15 \\
490 & 1.83 & -1.07 & 0.15 \\
517 & 1.77 & -0.92 & 0.15 \\
530 & 1.74 & -0.79 & 0.15 \\
\hline
\end{tabular}

curve of $18 \mu \mathrm{m}$ specimen, which will be examined in detail later in relation to GBS. The effect of raising temperature is manifested by the lower values of internal strength parameter $\sigma^{*}$ as one can readily see in the tables.

It is also interesting to note that the value of parameter $p$ characterizing dislocation permeability of strong barriers, that is, grain boundaries [9], was obtained as 0.15 regardless of testing temperatures or grain sizes, confirming the results reported previously $[5,13]$. The value of this parameter is believed to strongly depend on the boundary properties, 


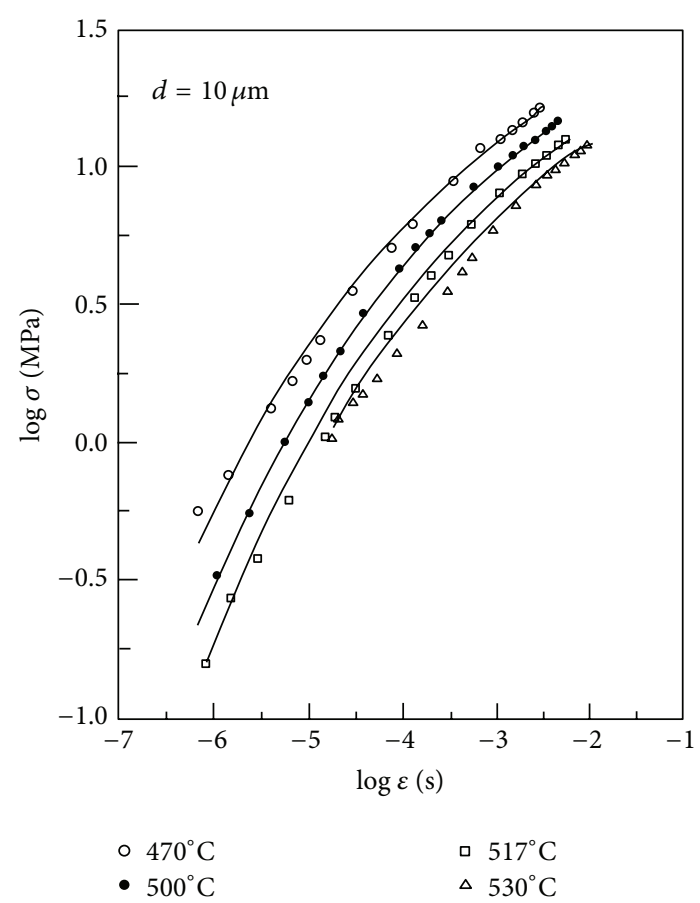

Figure 6: The effect of temperature on the flow behavior of 8090 Al-Li with the average grain size of $10 \mu \mathrm{m}$.

including its geometry and the properties of dislocations. From this point of view, it is necessary to examine the effect of variation in crystal structure on the value of this parameter, and interesting results have been obtained in Sn and Sncontaining alloys $[5,10]$. The value of $p$ in these alloys is 0.1 , much lower that that of materials with the close packed crystal structure. In the case of load relaxation test employed in this study, total strain applied to a specimen is about $1 \% \sim 2 \%$, very small in every case. Therefore, the parameter $p$ depends strongly on the boundary characteristics. A more systematic research in this regard is needed including microstructure observation.

4.2. Tensile Tests. The selected results of tensile tests conducted on the specimens having various grain sizes by varying the initial strain rate at the temperature of $530^{\circ} \mathrm{C}$ are given in Figure 7 . The largest elongation of about $800 \%$ was obtained in the specimen having $d=10 \mu \mathrm{m}$ under the initial strain rate of $\dot{\varepsilon}=5 \times 10^{-4} / \mathrm{s}$. As usually reported by other researchers, when the grain size was decreased and the initial strain rate lowered, the elongation clearly increased.

\section{Discussion}

One of the most important features of the internal variable approach employed in this study is that each deformation mechanism of high temperature deformation, that is, GMD and GBS, can be considered individually. It is, therefore, possible within this framework to quantitatively examine the respective contributions from GMD and GBS especially in SSP.
TABLE 5: The constitutive parameters for GBS ( $\dot{g}$ element) determined from the load relaxation test result of $8090 \mathrm{Al}-\mathrm{Li}$ alloy at $530^{\circ} \mathrm{C}$.

\begin{tabular}{lccc}
\hline$d(\mu \mathrm{m})$ & $\log \Sigma_{g}$ & $\log \dot{g}_{o}$ & $M_{g}$ \\
\hline 10 & 0.109 & -3.997 & 1.0 \\
18 & 0.122 & -4.461 & 1.0 \\
\hline
\end{tabular}

5.1. Grain Boundary Sliding. As mentioned earlier, the concave portion appears in the flow curves obtained at $530^{\circ} \mathrm{C}$ for the grain sizes of $10 \mu \mathrm{m}$ and $18 \mu \mathrm{m}$. By taking the difference between $\dot{\varepsilon}$ obtained directly from the relaxation test and $\dot{\alpha}$ estimated from (4) as the strain rate due to GBS, $\dot{g}$, according to (3), the flow curves for GBS could be constructed as shown in Figure 8. The constitutive parameters required in (8) were then determined again by a nonlinear curve fitting method, and the results are given in Table 5 . The bold solid lines in Figure 8 represent the composite curves predicted by (3), (4), and (8) assuming $\dot{\alpha} \cong 0$, and they show a good agreement with the experimental data. The most significant result obtained by this analysis is that the GBS can, in fact, be described as a Newtonian viscous flow characterized by the power index value of $M_{g}=1.0$, which can be confirmed experimentally by the work of Raj and Ashby [16]. As pointed out in an earlier work [5], they directly measured the sliding by loading helical springs wound of silver wire with a bamboo structure and found that the boundaries slide in a Newtonian viscous manner at high temperatures within a certain stress range. Above this range of stress, sliding appeared to be accompanied $\left(\sim 0.7 T_{M}\right)$ by plastic flow in the grains, leading to non-Newtonian behavior. Their result is very consistent with the analysis result of the present study, although the materials used in each study are very different. Experimental data themselves in Figure 6 do not show a Newtonian viscous behavior at all. The situation where the flow curves were obtained is thought to be very similar to the latter case of the study of Raj and Ashby [16], and it is clear that the intragranular slip plays an important role in SSP.

Under the optimal condition of SSP, the contribution of GBS to the total deformation $\left(\xi=\varepsilon_{\mathrm{GBS}} / \varepsilon_{\text {tot }}\right)$ has been reported to be $0.6 \sim 0.8$ [4]. In the situation where GBS is fully accommodated, $\xi$ has been proved to be over 0.9 [17]. It is, therefore, unlikely that diffusion creep can make a significant contribution more than $40 \%$ of total superplastic elongation [18]. While several measurements [19] indicated very limited dislocation activity in region II, recent direct measurements of the intragranular strain in a superplastic $\mathrm{Pb}-\mathrm{Sn}$ eutectic alloy have shown that the strain is oscillatory in nature, with both positive and negative components, and it makes no net contribution to the total elongation of the specimen [20]. This result is consistent with our discovery that the grains remain nearly equiaxed after superplastic deformation. Most of the determinations of $\xi$ in superplasticity experiments have relied upon the method proposed by Bell and Langdon [21]. We estimated $\xi(=\dot{g} / \dot{\varepsilon}=\delta g / \delta \varepsilon)$ value indirectly from Figure 6 to be about 0.6 at the stress level of $\sigma=2.5 \mathrm{MPa}$, which is within the range obtained by other experimental results mentioned previously. 


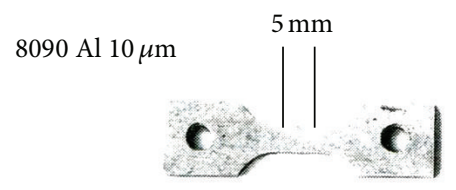

(A)

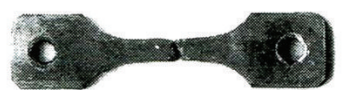

(B) $10^{-2} \mathrm{~s}$

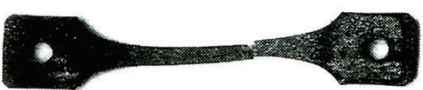

(C) $10^{-3} \mathrm{~s}$

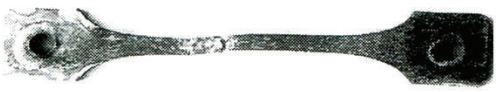

$10 \mathrm{~mm}$
(D) $5 \times 10^{-4} \mathrm{~s}$

(a)

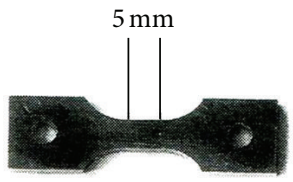

(A)

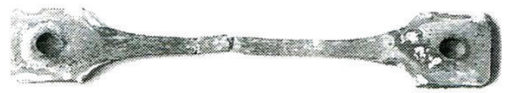

(B) $10 \mu \mathrm{m}$

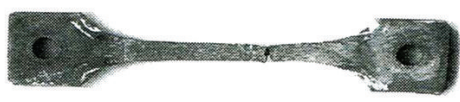

(C) $18 \mu \mathrm{m}$

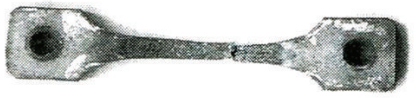

(D) $50 \mu \mathrm{m}$

(b)

FIgURE 7: Tensile test results of $8090 \mathrm{Al}-\mathrm{Li}$ alloy obtained at $530^{\circ} \mathrm{C}$ by varying the (a) strain rates and (b) grain sizes. A is untested specimen in both cases.

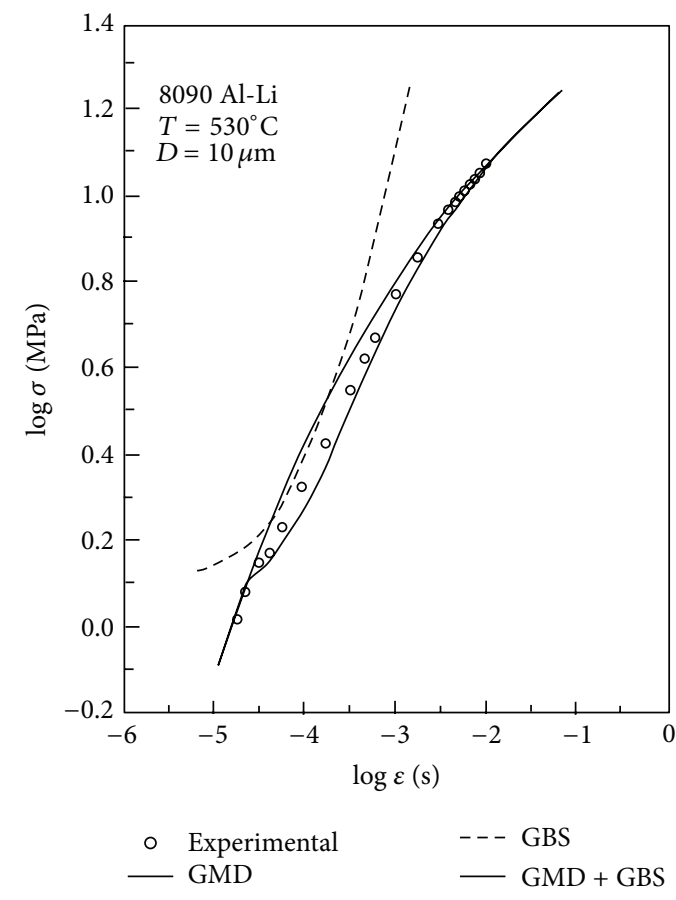

(a)

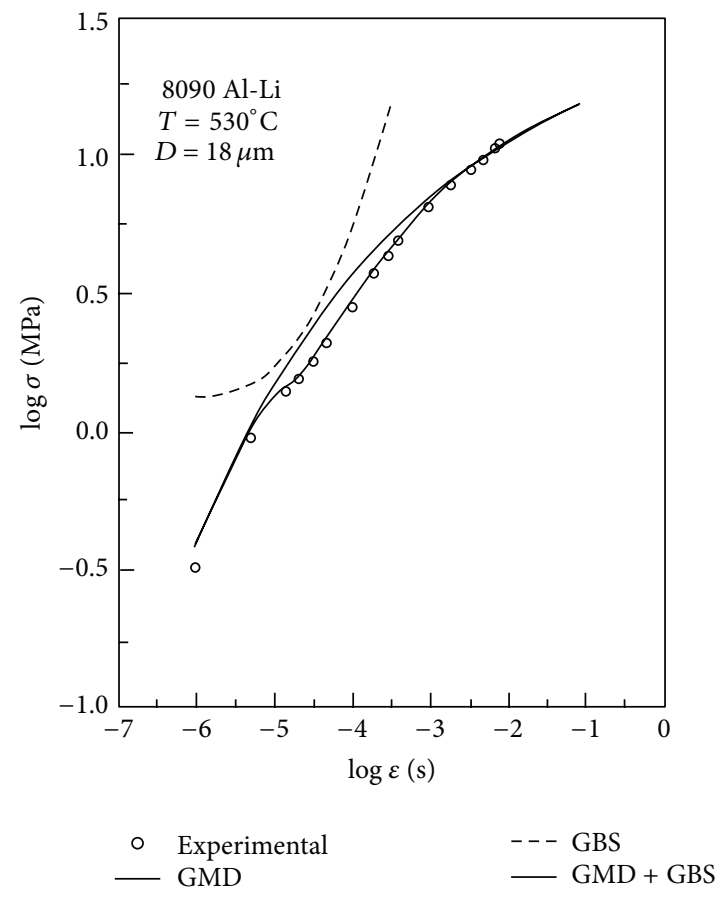

(b)

FIGURE 8: The flow curves are shown to consist of the contributions from GBS $(\dot{g})$ and the plastic deformation rate $(\dot{\alpha})$ for the specimens with the grain sizes of (a) $10 \mu \mathrm{m}$ and (b) $18 \mu \mathrm{m}$ at $530^{\circ} \mathrm{C}$.

In this study, the strain rate ranges, within which the effect of GBS is predominant, are $10^{-5} / \mathrm{s} \leq \dot{\varepsilon} \leq 10^{-3} / \mathrm{s}$ and $5 \times 10^{-5} / \mathrm{s}$ $\leq \dot{\varepsilon} \leq 5 \times 10^{-3} / \mathrm{s}$ for flow curves of specimens with $d=18$ and $10 \mu \mathrm{m}$, respectively. Perevezentsev et al. [22, 23] estimated that the upper and lower limits of strain rates, within which GBS can operate, would be an important deformation mechanism based on the concept of an "excited state" of boundary. The lower bound was calculated to be $10^{-6} / \mathrm{s} \sim 10^{-4} / \mathrm{s}$ and the upper bound to be about $5 \times 10^{-2} / \mathrm{s}$ with the typical values of SSP parameters, especially the grain size of $1 \sim 10 \mu \mathrm{m}$. The strain rate ranges for superplastic deformation due to GBS obtained in this study are also within these upper and lower bounds. We obtained the largest elongation of about $800 \%$ at the initial strain rate of $\dot{\varepsilon}=5 \times 10^{-4} / \mathrm{s}$ and at temperature of $530^{\circ} \mathrm{C}$ for 
the specimen with the average grain size of $d=10 \mu \mathrm{m}$ as in Figure 7, and this initial strain rate is clearly within the strain rate range mentioned previously in connection with the effect of GBS.

5.2. Temperature Effect. The experimental results given in Figures 4 to 6 reveal the effect of temperature on the flow behavior of 8090 Al-Li alloy. As previously mentioned, the effect of raising temperature is seen to make the flow curves shift noticeably toward the lower stress and the higher strain rate region. Figures 4 to 6 show that GBS is greatly affected by the test temperature. The contribution from GBS can be expected only at $530^{\circ} \mathrm{C}$ for the specimens of relatively small grain sizes, and this is verified by the tensile test result shown in Figure 7.

The value of the internal strength parameter $\sigma^{*}$ decreases with the increase of temperature as in Tables 2 to 4 . We believe that this is caused by a thermal softening effect which influences the mechanical properties of metals. The value of $\sigma^{*}$ in (4) represents the hardness state, as it was first used by Ha et al. [10], characterizing a typical microstructure of tested materials during the relaxation test. As shown in Table 4, in the temperature range within which the variation of $\sigma^{*}$ is negligible, the effect of increase in temperature is to increase the value of reference strain rate $\dot{\alpha}^{*}$, and so the flow curve shifts in the higher strain rate region. This effect combined with the thermal softening makes the flow curves shift toward the higher strain rate and the lower stress region.

From Figure 6 and Table 4, it is possible to determine the activation energies for the high temperature deformation mechanisms employed in this study. However, only the activation energy for GMD element was obtainable due to the restrictions of experimental conditions and the difficulty in data analysis. The activation energy $Q^{I}$ can be determined from the following relation obtained by differentiating (5):

$$
\left.\frac{\delta \ln \dot{\alpha}^{*}}{\delta(1 / T)}\right]_{\sigma^{*}}=-\left(\frac{Q^{I}}{R}\right) .
$$

Since the values of $\sigma^{*}$ obtained for the specimens with the grain size of $10 \mu \mathrm{m}$ do not change appreciably in the temperature range from $470^{\circ} \mathrm{C}$ to $530^{\circ} \mathrm{C}$ as seen in Table 4 , the relation between $\ln \dot{\alpha}^{*}$ and $1 / T$ is plotted in Figure 9 to determine the value of $Q^{I}$. The activation energy obtained was $Q^{I}=124.9 \mathrm{~kJ} / \mathrm{mole}$, which is very close to that for self-diffusion in $\mathrm{Al}$ (about $134 \mathrm{~kJ} / \mathrm{mole}$ ) [24]. Very similar results have been reported by $\mathrm{Pu}$ et al. [25] and Kwon et al. [26]. This value was also found to be very similar to the activation energy of Al-3Li-1.5Cu- $1 \mathrm{Mg}-0.1 \mathrm{Zr}$ alloy (about $140 \mathrm{~kJ} / \mathrm{mole}$ ) [27] in the as-extruded condition prior to the thermomechanical treatment for superplasticity. Under this condition, GBS cannot operate as an active deformation process for $\mathrm{Al}-3 \mathrm{Li}-1.5 \mathrm{Cu}-1 \mathrm{Mg}-0.1 \mathrm{Zr}$ alloy, and the activation energy of about $140 \mathrm{~kJ} / \mathrm{mole}$ is thought to be responsible for the plastic deformation by dislocation activities.

5.3. Grain Size Effect. To see the effect of grain size on the flow behavior of 8090 Al-Li alloy, the flow curves obtained

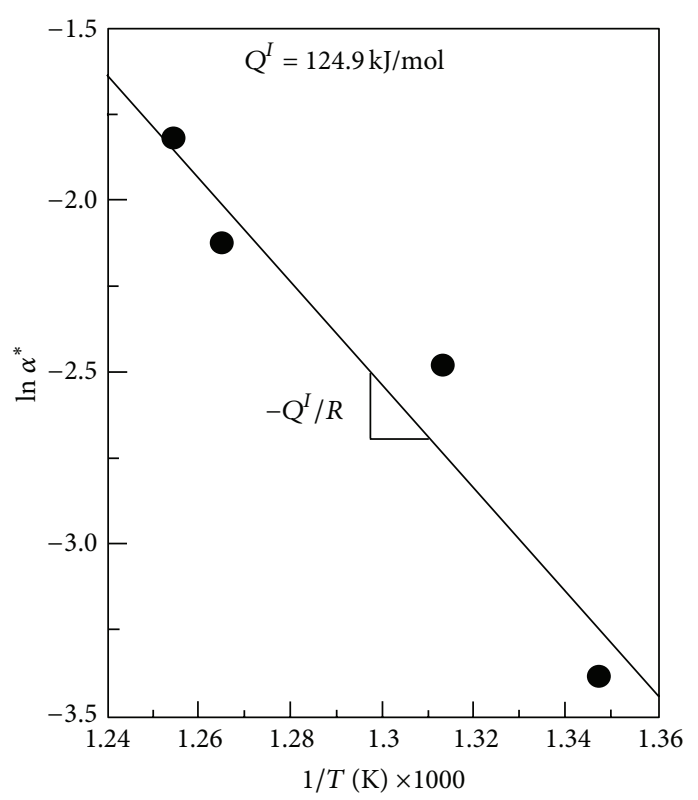

Figure 9: The plot of $\ln \dot{\alpha}^{*}$ versus $1 / T$ provides a means of determining the activation energy $Q^{I}$.

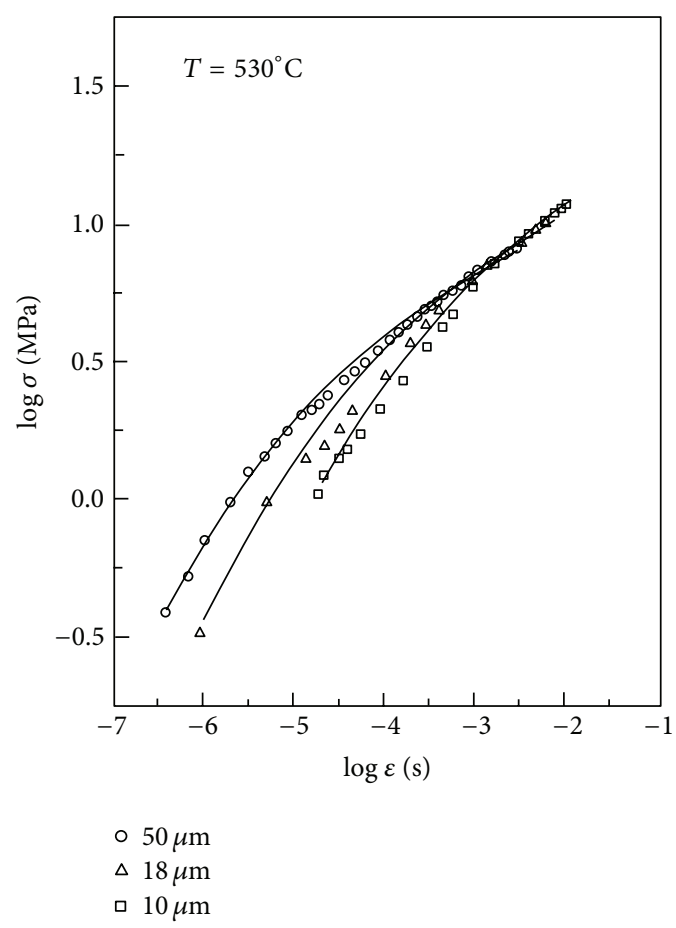

Figure 10: The effect of grain size on the flow behavior.

at $530^{\circ} \mathrm{C}$ were replotted as in Figure 10 . As the grain size decreases, the flow curves appear to shift toward the direction of the lower $\sigma$ and higher $\dot{\varepsilon}$ at $530^{\circ} \mathrm{C}$. Figure 10 clearly shows the effect of GBS on the flow behavior of materials. As seen in the tables, the value of internal strength parameter $\sigma^{*}$ increases with the decrease of grain size regardless of temperatures. In the cases where GBS can operate as a major deformation process, however, the flow stress of the specimen 


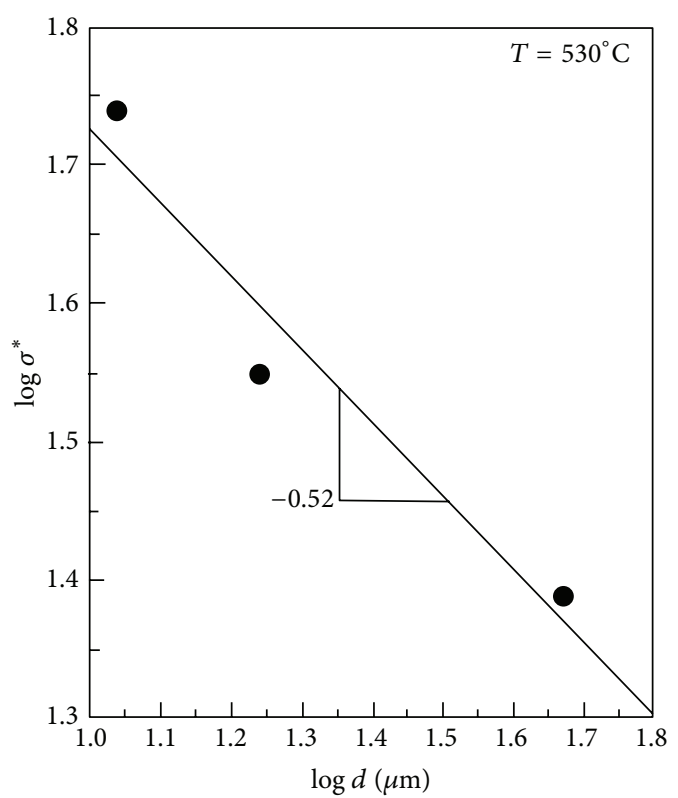

FIgURE 11: A Hall-Petch type relation between $\sigma^{*}$ and $d$ derived at $530^{\circ} \mathrm{C}$.

with smaller grain size appears to be much lower than that of specimen with larger grain size.

The values of $\sigma^{*}$ at $530^{\circ} \mathrm{C}$ listed in Tables 2 and 4 were next plotted against the grain size $d$ as shown in Figure 11 . Although the number of available grain sizes is not sufficient to determine the exact relation, a rough estimation for the slope of $\log \sigma^{*}$ versus $\log d$ provides the value of -0.52 , suggesting a modified Hall-Petch type relation between $\sigma^{*}$ and $d$ :

$$
\sigma^{*}=K d^{-1 / 2},
$$

where $K$ is a constant. It seems rather reasonable to replace the flow stress $(\sigma)$ in the classical Hall-Petch type relation with an internal structural variable $\sigma^{*}$ since the grain size $(d)$ is also a structural variable representing the microstructure. The temperature $530^{\circ} \mathrm{C}$ was chosen to exclude other dynamic effects, such as the precipitation of $\delta^{\prime}$ phase, during the tests. Very similar result has been obtained for $7475 \mathrm{Al}$ alloy [28].

5.4. Condition for SSP. Judging from the test results discussed previously, the $\log \sigma$ versus $\log \dot{\varepsilon}$ curve at high temperatures can, in fact, be considered to be a composite curve consisting of GBS $(\dot{g})$ and GMD $(\dot{\alpha})$ and accommodating the incompatibility caused by GBS. It can also be suggested that the superplastic deformation due to the GBS can only be observed under the following condition:

$$
\Sigma_{g} \leq \sigma \leq \sigma^{*} .
$$

To achieve this necessary condition for superplastic deformation caused by GBS, the temperature must be raised to reduce the static friction stress for GBS $\left(\Sigma_{g}\right)$ together with the increase in $\sigma^{*}$, which can be achieved through grain refinement according to the modified Hall-Petch relation given by (11).

\section{Conclusions}

By conducting a series of load relaxation and tensile tests on $8090 \mathrm{Al}-\mathrm{Li}$ alloy at high temperatures and by analyzing the results within the framework of the internal deformation variable theory, the following important results were obtained.

(1) The plastic flow curves of $\log \sigma^{I}$ versus $\log \dot{\alpha}$ can precisely be described by (4) for $8090 \mathrm{Al}-\mathrm{Li}$ alloy at temperatures ranging from $200^{\circ} \mathrm{C}$ to $530^{\circ} \mathrm{C}$.

(2) Our interpretation of the flow curves of superplastic $8090 \mathrm{Al}-\mathrm{Li}$ alloy led us to conclude that they consist of contributions from the GBS $(\dot{g})$ and the accommodating grain matrix plastic deformation $(\dot{\alpha})$ at high temperatures.

(3) The GBS appears to be a Newtonian viscous flow process characterized by the power index value of $M_{g}=1.0$ regardless of grain sizes.

(4) We proposed that a modified Hall-Petch type relation is occurring between the grain size and the internal strength variable $\left(\sigma^{*}\right)$ replacing the flow stress $(\sigma)$.

(5) The necessary condition for structural superplasticity was found to be $\Sigma_{g} \leq \sigma \leq \sigma^{*}$.

\section{Acknowledgments}

This work was partly supported by the National Hazard Mitigation Research Group of Korea (NHMRG), Grant funded by the National Emergency Management Agency (NEMA) (no. NEMA-NH-2011-49), and partly by the Ministry of Education, Science, and Technology (MEST), Gangwon province, Gangneung city, Gangneung Science Industry Foundation (GSIF) as the R\&D Project for Gangneung Science Park program. Woo Young Jung is grateful for the financial support by the National Research Foundation of Korea (NRF) Grant funded by the Korean Government (MEST) (no. 20110028531).

\section{References}

[1] K. Sotoudeh and P. S. Bate, "Diffusion creep and superplasticity in aluminium alloys," Acta Materialia, vol. 58, no. 6, pp. 19091920, 2010.

[2] T. G. Nieh and J. Wadsworth, "Fine structure superplastic intermetallics," International Materials Reviews, vol. 44, no. 2, pp. 5975, 1999.

[3] K. A. Padmanabhan and G. J. Davis, Superplasticity, Springer, Berlin, Germany, 1980.

[4] O. D. Sherby and J. Wadsworth, "Superplasticity-recent advances and future directions," Progress in Materials Science, vol. 33, no. 3, pp. 169-221, 1989.

[5] T. K. Ha and Y. W. Chang, "An internal variable theory of structural superplasticity," Acta Materialia, vol. 46, no. 8, pp. 2741-2749, 1998.

[6] M. F. Ashby and R. A. Verrall, "Diffusion-accommodated flow and superplasticity," Acta Metallurgica, vol. 21, no. 2, pp. 149163, 1973. 
[7] E. W. Hart, Stress Relaxation Testing, vol. 676 of ASTM Special Technical, ASTM International, Baltimore, Md, USA, 1979, A. Fox. Ed.

[8] E. W. Hart and H. D. Solomon, "Load relaxation studies of polycrystalline high purity aluminium," Acta Metallurgica, vol. 21, no. 3, pp. 295-307, 1973.

[9] Y. W. Chang and E. C. Aifantis, Proceedings of the 2nd International Conference on Constitutive Laws for Engineering Materials: Theory and Application, Eds. C. S. Desai et al., Tucson, Ariz, USA, Jan. 5-8, 1987, Elsevier, New York, NY, USA, 1987.

[10] T. K. Ha, C. S. Lee, and Y. W. Chang, "Plastic equation of state and load relaxation behavior of pure tin," Scripta Materialia, vol. 35, no. 5, pp. 635-640, 1996.

[11] H. C. Choi, T. K. Ha, H. C. Shin, and Y. W. Chang, "Formation kinetics of deformation twin and deformation induced $\varepsilon$ martensite in an austenitic Fe-C-Mn steel," Scripta Materialia, vol. 40, no. 10, pp. 1171-1177, 1999.

[12] L. E. Malvern, Introduction to Mechanics of a Continuous Media, Cambridge University Press, New York, NY, USA, 1975.

[13] E. W. Hart, "A phenomenological theory for plastic deformation of polycrystalline metals," Acta Metallurgica, vol. 18, no. 6, pp. 599-610, 1970.

[14] J. A. Wert, N. E. Paton, C. H. Hamilton, and M. W. Mahoney, "Grain refinement in 7075 aluminum by thermomechanical processing," Metallurgical Transactions A, vol. 12, no. 7, pp. 1267$1276,1981$.

[15] D. A. Woodford, "Measurement of the mechanical state of a low alloy steel at elevated temperature," Metallurgical Transactions A, vol. 6, no. 9, pp. 1693-1697, 1975.

[16] R. Raj and M. F. Ashby, "On grain boundary sliding and diffusional creep," Metallurgical Transactions A, vol. 2, no. 4, pp. 1113-1127, 1971.

[17] T. G. Langdon, "An evaluation of the strain contributed by grain boundary sliding in superplasticity," Materials Science and Engineering A, vol. 174, no. 2, pp. 225-230, 1994.

[18] T. G. Langdon, "A unified approach to grain boundary sliding in creep and superplasticity," Acta Metallurgica et Materialia, vol. 42, no. 7, pp. 2437-2443, 1994.

[19] L. K. L. Falk, P. R. Howell, G. L. Dunlop, and T. G. Langdon, "The role of matrix dislocations in the superplastic deformation of a copper alloy," Acta Metallurgica, vol. 34, no. 7, pp. 1203-1214, 1986.

[20] R. Z. Valiev and T. G. Langdon, "An investigation of the role of intragranular dislocation strain in the superplastic $\mathrm{Pb}-62 \% \mathrm{Sn}$ eutectic alloy," Acta Metallurgica et Materialia, vol. 41, no. 3, pp. 949-954, 1993.

[21] R. L. Bell and T. G. Langdon, "An investigation of grain-boundary sliding during creep," Journal of Materials Science, vol. 2, no. 4, pp. 313-323, 1967.

[22] V. N. Perevezentsev, V. V. Rybin, and V. N. Chuvil'deev, “The theory of structural superplasticity-I. The physical nature of the superplasticity phenomenon," Acta Metallurgica et Materialia, vol. 40, no. 5, pp. 887-894, 1992.

[23] V. N. Perevezentsev, V. V. Rybin, and V. N. Chuvil'deev, “The theory of structural superplasticity-II. Accumulation of defects on the intergranular and interphase boundaries. Accomodation of the grain-boundary sliding. The upper bound of the superplastic strain rate," Acta Metallurgica et Materialia, vol. 40, no. 5, pp. 895-905, 1992.

[24] O. D. Sherby and P. M. Burke, "Mechanical behavior of crystalline solids at elevated temperature," Progress in Materials Science, vol. 13, pp. 323-390, 1968.
[25] H. P. Pu, F. C. Liu, and J. C. Huang, "Characterization and analysis of low-temperature superplasticity in 8090 Al-Li alloys," Metallurgical and Materials Transactions A, vol. 26, no. 5, pp. 1153-1166, 1995.

[26] Y. N. Kwon, H. J. Koh, S. Lee, N. J. Kim, and Y. W. Chang, "Effects of microstructural evolution on superplastic deformation characteristics of a rapidly solidified Al-Li alloy," Metallurgical and Materials Transactions A, vol. 32, no. 7, pp. 1649-1658, 2001.

[27] J. Wadsworth, A. R. Pelton, and R. E. Lewis, "Superplastic AlCu-Li-Mg-Zr alloys," Metallurgical Transactions A, vol. 16, no. 12, pp. 2319-2332, 1985.

[28] T. K. Ha, H. J. Sung, K. S. Kim, and Y. W. Chang, "An internal variable approach to the grain size effect on the superplastic deformation behavior of a $7475 \mathrm{Al}$ alloy," Materials Science and Engineering A, vol. 271, no. 1-2, pp. 160-166, 1999. 

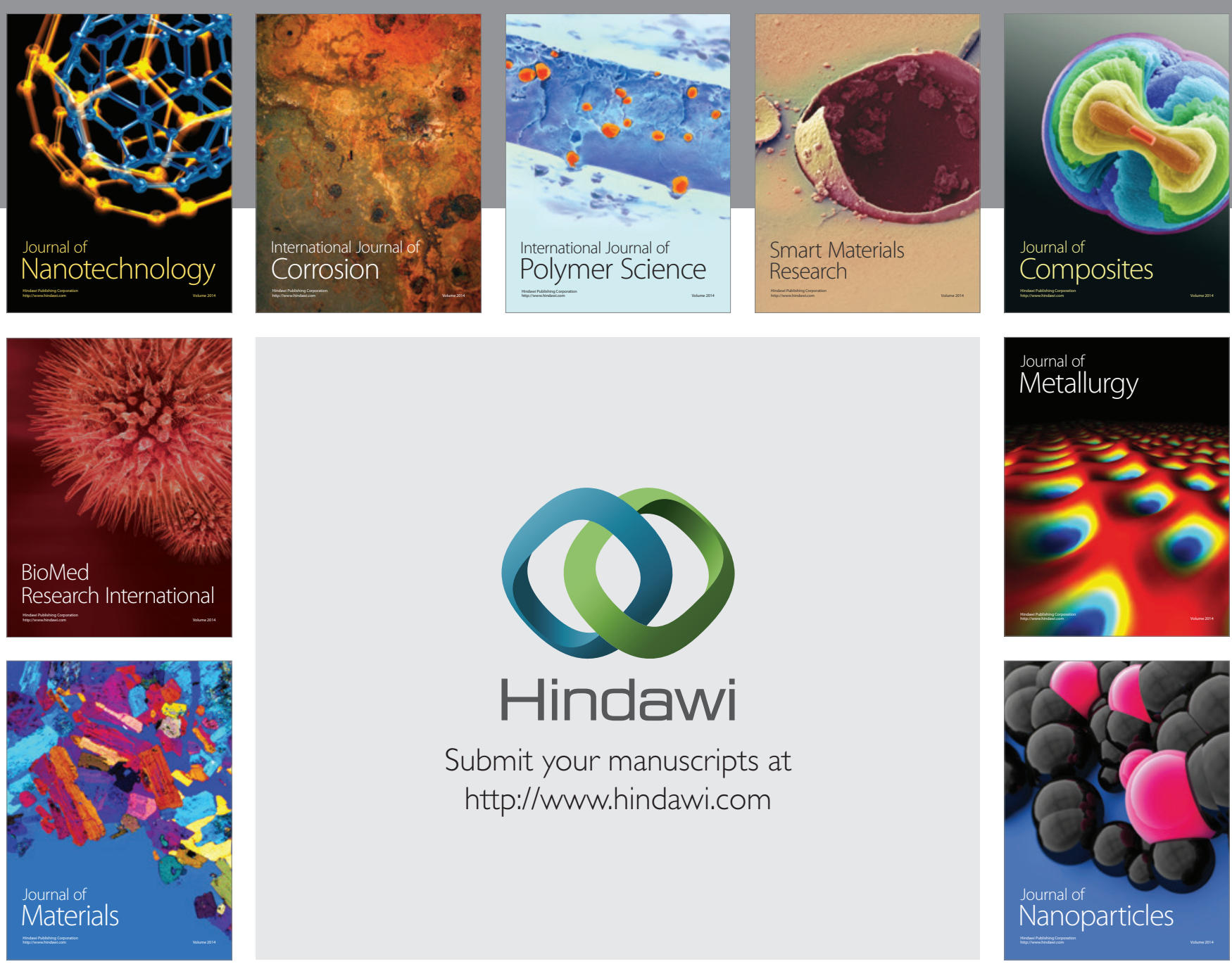

Submit your manuscripts at http://www.hindawi.com
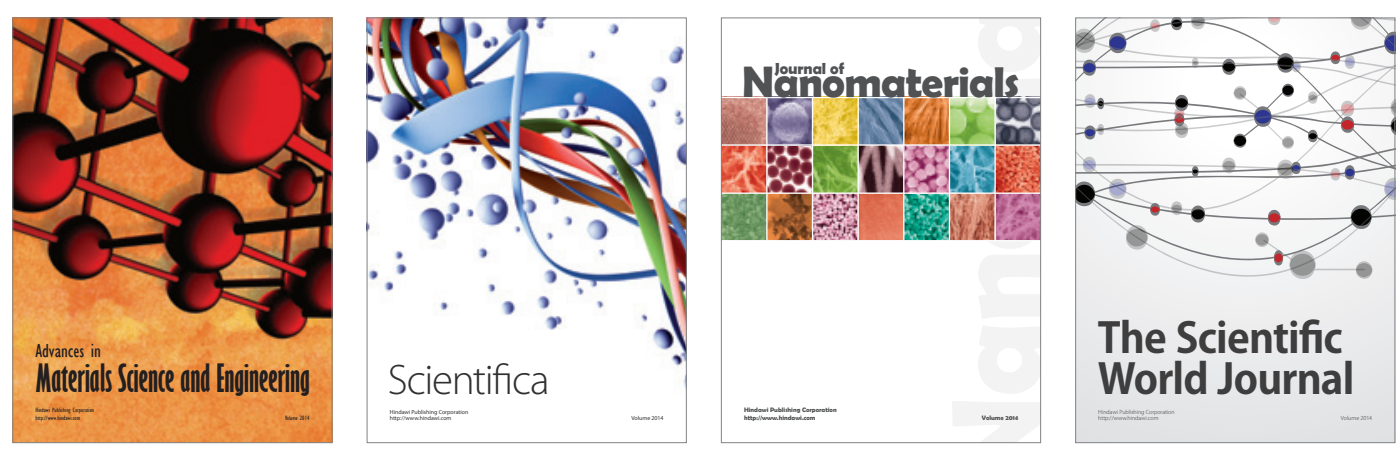

\section{The Scientific World Journal}
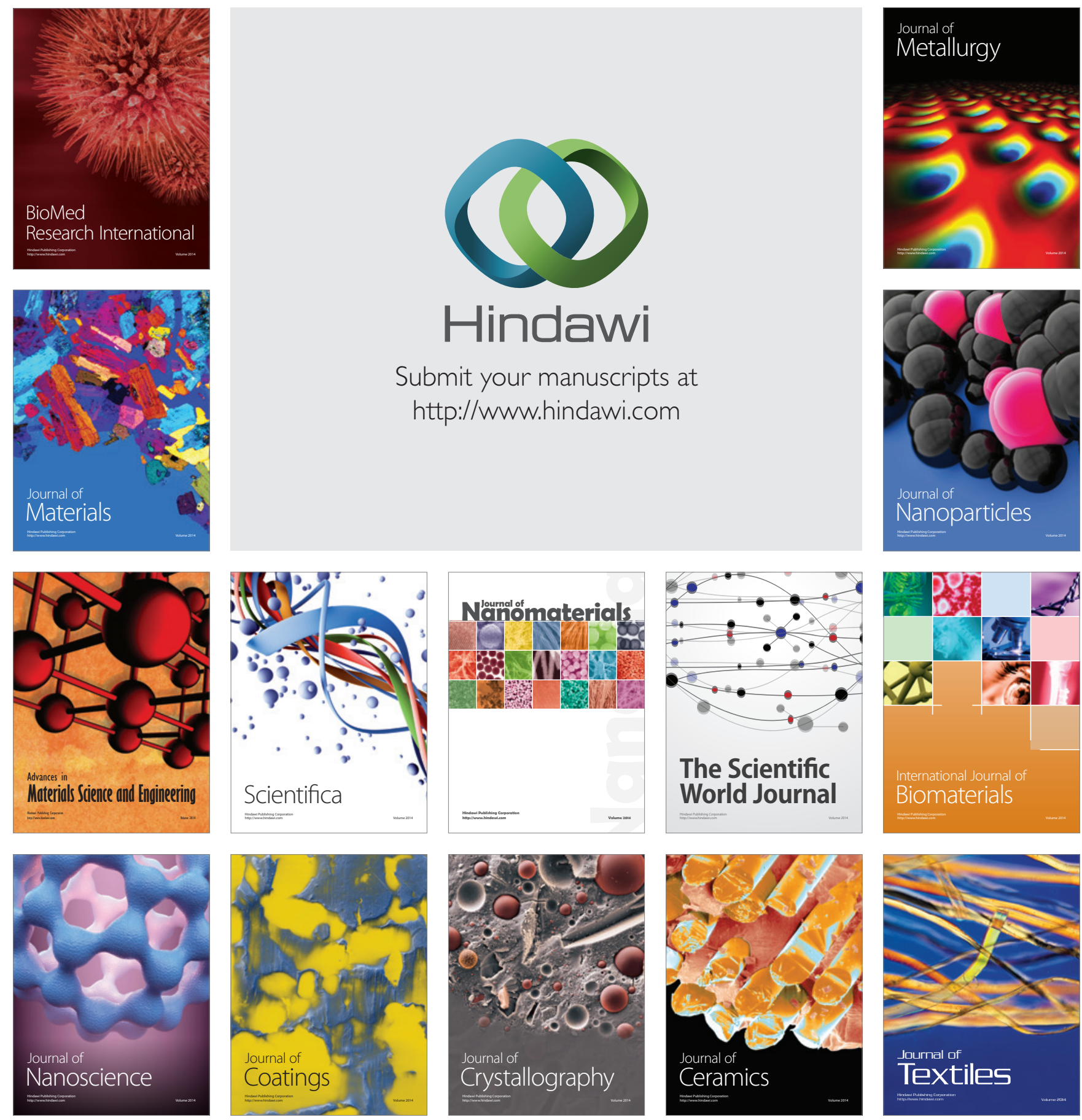